\title{
CONCEPÇÕES DE MEIO AMBIENTE E EDUCAÇÃO AMBIENTAL DE PROFESSORES DO ENSINO FUNDAMENTAL I
}

\author{
Marcelo André Dill ${ }^{1}$ \\ Irene Carniatto ${ }^{2}$
}

\begin{abstract}
Resumo: Compreender as concepções de meio ambiente é importante, pois, estas influenciam nas abordagens e estratégias pedagógicas utilizadas na Educação Ambiental. Assim, este estudo objetivou analisar as concepções de Meio Ambiente e Educação Ambiental de professores do Ensino fundamental I. A pesquisa apresenta abordagem quali-quantitativa, com dados oriundos de opiniões, coletadas através de um questionário. O estudo apontou concepções de Meio Ambiente, em sua maioria, naturalista e antropocêntrica. Já as concepções de Educação Ambiental que se mostram mais tradicionais, conservacionistas e preservacionistas, são refletidas abordagens pedagógicas que as reforçam.
\end{abstract}

Palavras-chave: Correntes Epistemológicas; Sustentabilidade; Conceitos; Educação.

Abstract: Understanding the conceptions of the environment is important, as they influence the pedagogical approaches and strategies used in Environmental Education. Thus, this study aimed to analyze the conceptions of the Environment and Environmental Education of elementary school teachers. The research presents a qualitative and quantitative approach, with data from opinions, collected through a questionnaire. The study pointed out conceptions of the Environment, mostly naturalistic and anthropocentric. The conceptions of Environmental Education that are more traditional, conservationists and preservationists, are reflected pedagogical approaches that reinforce them.

Keywords: Epistemological Currents; Sustainability; Concepts; Education.

\footnotetext{
1 Licenciado em Ciências Biológicas (UNIOESTE) Mestre em Desenvolvimento Rural Sustentável (UNIOESTE). Docente da Faculdade de Ensino Superior de Marechal Cândido Rondon - ISEPE/Rondon. E-mail: mad.bio@hotmail.com. Link para o Lattes: http://lattes.cnpq.br/4409534442630280.

2 Pesquisadora e Docente do Programa de Pós-Graduação em Desenvolvimento Rural Sustentável PPGDRS. Universidade Estadual do Oeste do Paraná - UNIOESTE. Campus de Marechal Cândido Rondon. Facilitadora da REDE BRASILEIRA DE EDUCAÇÃO AMBIENTAL- REBEA, da REASul e REAPR. E-mail: irenecarniatto@gmail.com. Link para o Lattes: http://lattes.cnpq.br/7508449720430708.
} 


\section{Introdução}

$\mathrm{Na}$ busca por satisfazer desejos e necessidades, o homem vem constantemente transformando e (re)construindo o espaço que ocupa. Essas transformações têm efeitos diretos sobre o meio ambiente e sobre a própria sociedade. Isso, porque somos interligados por meio de relações ecológicas, sociais e econômicas a um planeta fisicamente limitado.

Os processos de industrialização associados à mentalidade capitalista de produção e consumo exagerado desencadearam ações que visam apenas à obtenção de lucro, em nome de um modelo crescimento econômico, aumentando, dessa forma, os problemas socioambientais.

Assim, nosso planeta sofre duros golpes e, de acordo com Leff (2014, p. 49) são claros os efeitos dos impactos da exploração econômica sobre o ambiente:

[...] a destruição ecológica e o esgotamento dos recursos não são problemas gerados por processos naturais, mas determinados pelas formas sociais e pelos padrões tecnológicos de apropriação e exploração econômica da natureza.

Toda essa degradação ambiental mostra que o planeta atingiu seu limite, não conseguindo se recuperar sozinho, frente as ações humanas. $O$ mais preocupante disso tudo, é que todas as espécies, incluindo a humana, são dependentes do perfeito e harmonioso funcionamento do ambiente.

Diante do panorama atual, é fundamental o surgimento de uma nova percepção da realidade, que estimule as comunidades educativas, comerciais, políticas, de assistência à saúde e da vida cotidiana, ao ponto que os princípios ambientais se manifestem como princípios de educação, de administração e de política (CAPRA, 2001).

Para tanto, faz-se necessário uma reflexão sobre as práticas sociais, o que envolve uma articulação com a produção de sentidos sobre a Educação Ambiental (JACOB, 2003).

Segundo Reigota (2007), a Educação Ambiental visa não só a utilização racional dos recursos, mas também, a participação dos cidadãos nas discussões e decisões sobre a questão ambiental. Ela aponta para propostas pedagógicas centradas na conscientização, na mudança de comportamento, no desenvolvimento de competências, na capacidade de avaliação e participação dos educandos.

Cabe assim à Educação Ambiental favorecer o desenvolvimento de novos comportamentos, individuais ou coletivos a fim de superar as condições históricas atuais (TAMAIO, 2002).

E a escola é geralmente um agente fundamental na tomada de consciência e no desenvolvimento de novos comportamentos. Isto porque, 
conforme Segura (2001), a escola é um dos primeiros locais a absorver o processo de "ambientalização" da sociedade, tendo por este motivo, sua parcela de responsabilidade na busca de melhorar a qualidade de vida da população por meio da informação.

Portanto, o papel do professor também deve ser evidenciado neste processo, e, ainda, se mostra de suma importância na formação crítica e orientação da comunidade escolar, para a busca por melhorias de seus padrões de vida. Para Jacobi (2003), os professores são essenciais para impulsionar transformações em uma educação que assume o compromisso com a formação de valores de sustentabilidade, como parte de um processo coletivo.

Neste contexto, e entendendo a importância da Educação Ambiental no processo de mudança de comportamentos e de valores, objetivou-se compreender a concepção de Meio Ambiente e de Educação Ambiental de professores do Ensino Fundamental I e como estas estão inseridas em suas práticas pedagógicas.

\section{Meio Ambiente}

Cada pessoa tem sua própria concepção de meio ambiente, cujas características dependem de seus interesses, crenças e vivências. Assim, ao debater sobre as concepções de meio ambiente, ou propor projetos relacionados à Educação Ambiental, é necessário, primeiramente, conhecer as concepções de meio ambiente dos atores envolvidos na atividade.

De acordo com a Política Nacional do Meio Ambiente, Lei 6.938/1981, meio ambiente é compreendido como o conjunto de condições, leis, influências e interações de ordem física, química e biológica, que permite, abriga e rege a vida em todas as suas formas (BRASIL, 1981).

Reigota, por sua vez, define meio ambiente como sendo:

(...) um lugar determinado e/ou percebido onde estão em relações dinâmicas e em constante interação os aspectos naturais e sociais. Essas relações acarretam processos de criação cultural e tecnológica e processos históricos e políticos de transformação da natureza e da sociedade (REIGOTA, 2009, p. 21).

Dessa forma, o meio ambiente compreende um campo de interações entre a cultura, sociedade e os aspectos físicos e biológicos da vida, no qual os termos dessa relação se alteram de forma mútua e dinâmica. Portanto, o meio ambiente é espaço relacional, onde o homem pertence à uma teia de relações da vida natural, social e cultural e que nela interage (CARVALHO, 2012). 
Inúmeras são as definições encontradas para o termo Meio Ambiente e sendo ele um dos objetos de estudo e de ação da Educação Ambiental, é fundamental que os educadores ambientais conheçam e compreendam suas múltiplas facetas, para que possam agir de forma mais eficiente (SAUVÈ, 2005a).

Sobre isso, Sauvè (1997) aponta que o ambiente pode ser compreendido como natureza, para apreciar, respeitar e preservar; como recurso, que pode ser gerido; como problema, a ser prevenido e resolvido; como sistema, a ser compreendido; como lugar em que se vive; como biosfera, que comporta a vida; e como projeto comunitário, onde socializamos.

Portanto, conhecer e compreender as concepções de meio ambiente se torna indispensável na Educação Ambiental. Como afirma Reigota (2007), só assim poderão ser realizadas ações de Educação Ambiental eficazes, pois estas representações de meio ambiente estão relacionadas a diferentes abordagens e estratégicas em Educação Ambiental (SAUVĖ, et al., 2000).

\section{Educação Ambiental}

A Educação Ambiental se transformou em prioridade a partir do momento que passou a desenvolver suportes críticos e analíticos na formação do ser humano. Frequentemente está relacionada ao termo meio ambiente, o que torna indispensável compreendermos sua função e seus objetivos no entendimento das relações entre o homem e o ambiente.

A Lei 9.795/99 (BRASIL, 1999), em seus artigos iniciais, traz a Educação Ambiental como componente essencial e permanente da educação nacional, devendo estar presente em todos os níveis e modalidades do processo educativo, seja formal ou não-formal. Segundo Dias (2004, p. 523) Educação Ambiental é:

[...] um processo permanente no qual os indivíduos e a comunidade tomam consciência do seu meio ambiente e adquirem novos conhecimentos, valores, habilidades, experiências e determinação que os tornam aptos a agir e resolver problemas ambientais, presentes e futuros.

Mauro Guimarães (2004) defende que a Educação Ambiental precisa ser emancipatória e crítica, com o objetivo de promover ambientes educativos que mobilizem processos de intervenção sobre a realidade e os problemas socioambientais. Assim, tal educação, precisa ultrapassar as armadilhas paradigmáticas e oferecer um processo educativo no qual os educandos e educadores possam contribuir com ações de transformação na crise socioambiental. 
Diante das condições sociais vividas na atualidade, é imprescindível e urgente tratarmos os problemas ambientais dentro de uma abordagem participativa, tornando a Educação Ambiental um processo crítico e inovador, sendo acima de um processo de educação, um ato político de transformação social (JACOBI, 1997).

Porém, de acordo com Sauvé (2005b), quando se aborda o campo da Educação Ambiental, percebe-se que apesar da preocupação comum com o ambiente e o reconhecimento do seu papel para melhoria deste, diferentes discursos e maneiras de se conceber e de praticar a Educação Ambiental são identificados. Por isso a autora utiliza a ideia de correntes de Educação Ambiental, buscando descrever as várias formas de trilhar esses caminhos, e, definindo quinze diferentes correntes, baseadas na percepção do meio ambiente; da intenção central da Educação Ambiental e de suas estratégias.

\section{Metodologia}

O presente trabalho se configura em um estudo de caráter descritivo, pois, conforme Gil (2002) tem como objetivo principal a descrição das características de determinado grupo, estabelecendo de relações entre diferentes variáveis.

O instrumento de coleta de dados foi um questionário com total de 11 questões das quais 7 são perguntas com escalas variadas e 4 questões de perguntas abertas, aplicado entre julho e agosto de 2018. A população entrevistada era composta por 25 professores do Ensino Fundamental I, todos da mesma escola, que foram convidados a participar do estudo.

Dessa forma, a pesquisa apresenta abordagem quali-quantitativa, pois, os dados são oriundos de opiniões, o que de acordo com Richardson (1999) é uma qualidade, um reconhecimento sobre algo. A abordagem qualitativa se refere a análise da opinião pessoal que os respondentes irão dar sobre o fenômeno pesquisado. Já a abordagem quantitativa se refere à estatística utilizada para analisar as variáveis do estudo.

Os dados foram tratados de forma numérica e analisados descritivamente. Para a análise das concepções, utilizou-se a metodologia de Investigação Narrativa proposta por Carniatto (2002), em que se buscou evidenciar, enaltecer e valorizar as riquezas sociais, culturais e históricas incutidas nos dados coletados, bem como a análise de conteúdo, de caráter essencialmente qualitativo, desenvolvida por Bardin (2010).

$\mathrm{Na}$ análise e discussão dos dados coletados, os professores foram identificados, aleatoriamente, pela abreviatura "Prof." e por um número sequencial, sendo tratados como: Prof.1; Prof.2; e assim sucessivamente até Prof.25. As categorias de análise das concepções de Meio Ambiente e Educação Ambiental dos participantes foram identificadas com base em Sauvè (1997, 2005a, 2005b). 


\section{Resultados e Discussão}

Dos 25 questionários distribuídos, retornaram 21 (84\%). Ressalta-se aqui que a participação dos professores era voluntária.

Os professores que participaram da pesquisa, em sua maioria, $80,95 \%$ têm formação inicial nível Magistério e uma licenciatura em área diversa, e $19,05 \%$ têm formação inicial nível médio magistério e Pedagogia. Desses, verificou-se que 95,24\% apresentam pós-graduação a nível Latu Sensu em alguma área da educação. Em sua maioria, apresentam mais de 15 anos de experiência profissional, como mostra a Tabela 1.

Tabela 1: Tempo de experiência como professor do ensino fundamental.

\begin{tabular}{lc}
\hline \multicolumn{1}{c}{ Tempo experiência (anos) } & $\mathbf{N}^{\circ}$ Professores \\
\hline $1-5$ anos & 1 \\
$6-10$ anos & 4 \\
$11-15$ anos & 3 \\
$15-20$ anos & 3 \\
+20 anos & 10 \\
\hline Total & $\mathbf{2 1}$ \\
\hline
\end{tabular}

Fonte: Os autores

Identificou-se que, $42,86 \%$ dos professores cursaram, na sua formação inicial disciplina específica de Educação Ambiental, e 90,48\% realizaram alguma formação na área de Educação Ambiental, no âmbito da formação continuada.

De acordo com a Lei no 9795/99, a dimensão ambiental deve constar nos currículos de formação de professores, em todos os níveis e em todas as áreas, e professores em atividade devem receber formação complementar e continuada (BRASIL, 1999). Portanto, a formação de profissionais da educação, no âmbito da dimensão ambiental, é fundamental, dada à emergência da necessidade de conscientização e capacitação prática dos cidadãos para a sustentabilidade socioambiental (CARNEIRO, 2008).

\section{Temática Meio Ambiente}

Dos 21 professores que participaram do estudo, 18 afirmaram realizar atividades relacionados à Educação Ambiental e Meio Ambiente durante suas práticas pedagógicas. A maioria dos professores considerou importante a inclusão dessa temática durante as aulas. Apenas 2 professores, consideraram a inclusão pouco importante.

Deve-se ressaltar que a inserção desta temática é importante, principalmente no início da vida acadêmica, para buscarmos alcançar novas formas de percepção e concepção do Meio Ambiente. Indiferente da área de atuação, ou de formação do professor, inserir esta temática em sua prática pedagógica é um passo fundamental na busca de uma consciência coletiva de ambiente e do papel que a humanidade tem em preservá-lo e conservá-lo. 
Quanto à forma utilizada para a inserção desta temática no processo pedagógico, observou-se que a maioria dos professores faz uso de metodologias convencionais, usuais, como mostra a Tabela 2.

Tabela 2: Principais formas de trabalho utilizado para incluir a Educação Ambiental e Meio Ambiente no trabalho em sala de aula.

\begin{tabular}{lc}
\hline Principais atividades & № de citações \\
\hline Atividades de leitura e interpretação de textos & 18 \\
Atividades do livro didático & 15 \\
Atividades em datas específicas & 10 \\
Filmes e Vídeos & 8 \\
Pesquisas & 7 \\
Visitas e passeios & 4 \\
Projeto & 2 \\
\hline Total & $\mathbf{7 1}$ \\
\hline
\end{tabular}

Fonte: Os autores.

Embora a Educação Ambiental possa utilizar inúmeros métodos de ensino, o mais adequado deles é aquele que o professor estabelece de acordo com as características de seus alunos, sendo a metodologia expositiva pouco recomendável, embora útil, quando se abre espaço para os discussões e questionamentos (REIGOTA, 2009).

Para o autor "[...] é necessário que a prática pedagógica seja criativa e democrática, fundamentada no diálogo entre professor e alunos" (REIGOTA, 2007 , p. 26), prática esta que depende diretamente da concepção que o professor tem de meio ambiente.

Nesse sentido, e de acordo com Penteado (2003, p. 53):

Uma coisa é ler sobre o meu meio ambiente e ficar informado sobre ele, outra é observar diretamente o meu meio ambiente, entrar em contato direto com os diferentes grupos sociais que 0 compõe, observar como as relações sociais permeiam o meio ambiente e o exploram, [...] sabemos que se aprende a participar, participando.

Ao serem perguntados sobre quando incluem a temática meio ambiente e Educação Ambiental em suas aulas, 10 professores responderam inseri-las diariamente, de forma interdisciplinar, 6 afirmaram incluir a temática sempre que surge uma situação ou oportunidade, 3 afirmaram inseri-la quando a escola propõe atividades, geralmente em datas comemorativas e 2 professores inserem a temática quando esta se relaciona ao conteúdo estudado, ou quando o material didático sugere atividade. 
O uso de práticas interdisciplinares se mostra fundamental, isso porque, temas que discutem a Educação Ambiental quando trabalhados numa perspectiva de interdisciplinaridade proporcionam situações mais significativas aos alunos e favorecem para a construção crítica dos saberes referentes ao meio ambiente.

No entanto, o professor precisa assumir uma postura reflexiva para, numa perspectiva crítica, desenvolver práticas que articulem a educação e o meio ambiente. Além disso, é preciso ter uma atuação ecológica sustentada por princípios de criatividade, possibilitando a sensibilização de seus alunos e uma crescente participação (JACOBI, 2005).

Sobre temas geradores, usados na prática pedagógica, para a inclusão da temática ambiental foi possível identificar nas respostas dos professores, temas comuns e habituais, como lixo, água, desmatamento e poluição, como mostra a Tabela 3.

Tabela 3: Quais assuntos (temas) usados com mais frequência para incluir a temática Meio Ambiente e Educação Ambiental nas aulas.

\begin{tabular}{|c|c|c|}
\hline Principais Atividades & № de Citações & $\%(\mathrm{~N}=121)$ \\
\hline Lixo/coleta seletiva & 18 & $14,88 \%$ \\
\hline Água & 16 & $13,22 \%$ \\
\hline Desmatamento & 16 & $13,22 \%$ \\
\hline Aquecimento Global & 15 & $12,40 \%$ \\
\hline Poluição (ar, solo, água) & 11 & $9,09 \%$ \\
\hline Preservação ambiental & 10 & $8,26 \%$ \\
\hline Solo & 7 & $5,79 \%$ \\
\hline Extinção de Espécies animais e vegetais & 6 & $4,96 \%$ \\
\hline Problemas sociais & 5 & $4,13 \%$ \\
\hline Agrotóxicos & 5 & $4,13 \%$ \\
\hline Sustentabilidade/Desenvolvimento Sustentável & 4 & $3,31 \%$ \\
\hline Outros & 8 & $6,61 \%$ \\
\hline Total & 121 & $100 \%$ \\
\hline
\end{tabular}

Fonte: Os autores.

Observa-se a tendência de incluir temas mais voltados às problemáticas ambientais e que remetem à preservação e conservação ambiental, demonstrando uma tendência conservacionista e preservacionista.

Cabe ressaltar, que não existe um tema ideal para a inserção da temática ambiental, porém, de acordo com Tozoni-Reis (2006) e Reigota (2009), temas ambientais, ligados ao cotidiano e a realidade socioambiental, identificados pelo professor e pelos alunos, devem ser tomados como ponto de partida. 
No que se refere aos projetos voltados para essas temáticas, os professores foram unânimes em afirmar que a escola não apresenta projetos definidos e, quando existem, são pontuais e trabalhados de forma isolada. Essa falta de projetos foi apontada como uma das principais dificuldades encontradas pelos professores no trabalho com Educação Ambiental, seguida da ausência de formação, como mostra a Tabela 4.

Tabela 4: Dificuldades apontadas no trabalho com Educação Ambiental.

\begin{tabular}{lcc}
\hline Dificuldade & Frequência & \% (N = 68) \\
\hline Ausência de projeto definido na escola & 21 & $32,81 \%$ \\
Ausência de formação continuada na área (recente) & 11 & $17,19 \%$ \\
Falta de apoio de equipe pedagógica, direção, secretaria de & 10 & $15,62 \%$ \\
educação & 8 & $12,50 \%$ \\
Falta de tempo para cumprir conteúdo programático & 6 & $9,38 \%$ \\
Falta de materiais didáticos & 5 & $7,81 \%$ \\
Dificuldade de trabalhar de forma interdisciplinar & 3 & $4,69 \%$ \\
Dificuldade para sair da escola visitas, passeios & $\mathbf{6 8}$ & $\mathbf{1 0 0 \%}$ \\
\hline TOTAL &
\end{tabular}

Fonte: Os autores.

Não existe receita pronta ou milagre que resolva todas os problemas relacionados às práticas educacionais, porém, é importante que haja uma ação coletiva para a discussão do conhecimento e para a troca de saberes, proporcionando assim, novas possibilidades no processo pedagógico

Guimarães (2007) aponta que muitas dificuldades apresentadas na prática pedagógica da temática ambiental são consequências de uma visão fragmentada da formação docente, o que interfere na prática ao fazer oposição aos rompimentos de práticas conservadoras.

Nesse contexto, Sauvè (2005b) traz uma importante análise ao dizer que cabe ao docente definir seu nicho educacional na Educação Ambiental, em função do contexto particular de sua intervenção, do grupo-alvo a que se dirige e dos recursos de que dispõe. Trata-se de escolher objetivos e estratégias mais oportunas.

\section{Concepções de Meio Ambiente}

As concepções de Meio Ambiente apresentadas foram analisadas e classificadas de acordo com as concepções tipológicas de meio ambiente descritas por Sauvè $(1997,2005 a)$, como mostra a Tabela 5. Essas concepções tipológicas não são excludentes, sendo a classificação realizada através da concepção de maior ênfase na definição. 
Tabela 5: Análise das concepções de Meio Ambiente, segundo a definição dos professores.

\begin{tabular}{ll}
\hline Concepções Tipológicas (Sauvè, 1997, 2005a) & № Professores \\
\hline Ambiente como a natureza & 6 \\
Ambiente como lugar para viver & 4 \\
Ambiente como recurso & 4 \\
Ambiente como projeto comunitário & 3 \\
Ambiente como a biosfera & 2 \\
Ambiente como problema & 2 \\
\hline Total & $\mathbf{2 1}$ \\
\hline
\end{tabular}

Fonte: Os autores.

Destacaram-se, dentre as definições apresentadas pelos professores, aquelas relacionadas às concepções de meio ambiente como natureza, o lugar onde viver e como recurso.

As concepções tipológicas de ambiente como natureza, seguem a característica do ambiente como meio natural, os rios, lagos e mares, os animais as plantas, a diversidade da vida, aspectos estes, que precisam ser respeitados, preservados, como mostram os exemplos abaixo, das narrativas dos professores participantes da pesquisa:

O meio ambiente é tudo natureza que nos cerca, os animais, as plantas, o mundo natural (Prof.1).

Meio ambiente são os espaços naturais, a natureza, que demos o dever de conservar (Prof.12).

De acordo com Sauvè (1997, 2005a), o ambiente como natureza é o ambiente original e "puro" do qual os seres humanos estão separados, contudo tem o dever de aprender a se relacionar, buscando enriquecer a qualidade de ser, portanto, algo a ser respeitado e admirado. Essas concepções se enquadram também na visão naturalista, na qual o meio ambiente é sinônimo de natureza intocada, evidenciando somente aspectos naturais (REIGOTA, 2007).

O meio ambiente como recurso, também esteve presente dentre as concepções apresentadas por alguns professores:

É nosso planeta que nos fornece os recursos necessário para a sobrevivência dos seres vivos e do homem (Prof.5).

É o lugar de onde tiramos nosso sustento, que nos fornece os recursos necessários e que necessitam ser preservados, para a nossa sobrevivência (Prof.17).

Nesta, o ambiente é percebido como fonte de recursos, como provedor do sustento do ser humano. O ambiente é percebido como recurso limitado, deteriorável e degradado, que pode ser gerenciado e administrado (SAUVÈ, 1997). 
O ambiente como problema, identificado como nosso ambiente biofísico, ameaçado, é o sistema de suporte a vida, que sofre com a poluição e degradação ambiental (SAUVĖ, 1997). As definições classificadas nesta subcategoria enfatizam problemas ambientais, como mostram os exemplos abaixo:

[...]ambiente que vem sendo degradado, destruído, desmatado, poluído. (Prof.6).

[...]o ambiente que sustenta toda as formas de vida e que vem sofrendo com vários problemas causados pelo homem (Prof.13).

Para Fernandes et al. (2002) essa concepção de ambiente enquanto problema, apesar de apresentar uma visão naturalista do ambiente, carrega a ideia de recursos naturais que precisam ser utilizados de forma racional.

Nos conceitos relacionados à concepção de meio ambiente como natureza, problema e recurso, percebe-se que o homem está dissociado do meio, devendo este respeitá-lo, preservá-lo, usá-lo para seu bem, demonstrando-se como concepções utilitaristas, ao mesmo tempo que naturalistas e antropológicas, como apresentado por Reigota (2009).

A concepção tipológica de ambiente como lugar para viver fica clara nas seguintes definições:

É o espaço onde vivemos em sociedade, transformado pela ação humana, pelo qual somos todos responsáveis (Prof.2).

Meio ambiente é o local onde a gente vive, é a casa da gente, a escola, a cidade, o bairro, o nosso jardim, a rua da nossa casa, os todos os locais nos quais temos influência (Prof.14).

Nesta concepção, o ambiente é percebido como os espaços do nosso cotidiano, a escola, nossa casa, vizinhança, local trabalho e de lazer. Espaços estes pelos quais devemos desenvolver o senso de pertencimento, de apreciação, aqueles que devemos. Ele é caracterizado pelo ser humano, nos seus aspectos socioculturais, tecnológicos e históricos (SAUVĖ, 1997, 2005a).

Já o ambiente enquanto biosfera é caracterizado pela interdependência entre os seres vivos e os componentes abióticos. Para Sauvè (1997) o ambiente é percebido como um lugar de consciência planetária e a Terra como uma matriz de vida. As definições abaixo, se enquadram nesta subcategoria:

O meio ambiente é o nosso belo e singular planeta, onde se desenvolve a vida na terra, ou seja, é a planeta com todos os seres vivos, objetos inanimados, que precisa ser respeitado e preservado (Prof.7). 
O meio ambiente engloba todos os elementos vivos e não-vivos que se complementam, se relacionam, nosso planeta, nossa casa maior (Prof.8).

A concepção tipológica de ambiente como projeto comunitário é aquela em que o ambiente é onde estamos inseridos e nos envolvemos. Para Sauvè (1997) ele é o ambiente da coletividade humana. Esta concepção se fez presente nas seguintes definições:

Meio ambiente é o meio onde todos nós estamos inseridos, nossas relações sociais, o espaço que construímos enquanto sociedade (Prof.10).

Meio ambiente é todo o espaço que ocupamos, vivemos, convivemos e construímos como sujeitos e sociedade, hoje e no futuro (Prof.18).

As concepções de meio ambiente que apresentam visão de lugar, biosfera e projeto comunitário, mostram relações recíprocas entre natureza e sociedade, incluindo o homem como parte integrante do meio. Assim podem ser consideradas, conforme Reigota (2007), como globalizantes, pois caracterizarem o ambiente com suas relações entre a natureza e a sociedade, englobando aspectos naturais, políticos, sociais, econômicos, filosóficos e culturais.

Contudo, Oliveira, et al. (2007) explicam que na busca por uma definição para o termo "meio ambiente", surgem inúmeras possibilidades e isso pode gerar controvérsias. Assim, a percepção de meio ambiente ocorre quando acontece, por parte do ser humano, a tomada de consciência e de compreensão do todo, despertando a percepção do ambiente em que se está inserido (BEZERRA et al.,2008).

Assim, a forma como se concebe o meio ambiente influencia diretamente no trabalho pedagógico, uma vez que define a prática pedagógica da Educação Ambiental e a seleção de conteúdo a ser inserido nesta prática. Portanto, conhecer as concepções, pode ser o ponto de partida para situar problemas ambientais, inclusive em espaços escolares.

\section{Concepções de Educação Ambiental}

Destacaram-se, entre as correntes identificadas nas definições apresentadas pelos professores, aquelas consideradas mais tradicionais, como mostra a Tabela 6. 
Tabela 6: Análise do conceito de Educação Ambiental apresentados pelos professores.

Correntes de Educação Ambiental (Sauvè, 2005b) № Concepções

Científica

11

Naturalista

8

Conservacionista/recursista $\quad 7$

Correntes tradicionais

Moral/Ética

6

Humanista

Resolutiva

5

Sistêmica

Ecoeducação

Crítica

Sustentabilidade

Fonte: Os autores.

Contatou-se que todas as concepções apresentadas, se enquadram em mais de uma corrente, o que segundo Sauvè (2005b) é resultado da análise realizada, sendo possível que uma mesma concepção pode corresponder a diferentes correntes, uma vez que estas não são excludentes.

A visão dos professores de que é possível aproximar a Educação Ambiental da Ciência, fazendo com que o indivíduo aprenda e desenvolva conhecimentos relativos ao meio ambiente, se enquadram na corrente científica da Educação Ambiental, como mostram alguns exemplos abaixo:

É a educação, transmissão de conhecimentos, voltada para o meio ambiente, [...] (Prof.1).

São processos e conhecimentos científicos voltados para a preservação do meio ambiente [...] (Prof.2).

Essa corrente, segundo Sauvè (2005b) enfatiza que o processo científico, com o objetivo de abordar as realidades e os problemas ambientais de forma a compreendê-los, identificando relações entra causa e efeito. O objetivo principal é adquirir conhecimentos em ciências ambientais e desenvolver habilidades relativas ao processo de experimentação científica.

A aproximação da Educação Ambiental com a educação científica pode ser potencialmente enriquecedora e muito proveitosa, se a transmissão de conhecimentos de forma interdisciplinar promover uma transformação do indivíduo.

Outra corrente que se destacou nas concepções dos professores foi a naturalista, centrada na relação do homem com a natureza. O enfoque educativo está centrado em aprender com e sobre a natureza, em associar a criatividade humana à natureza (SAUVĖ, 2005b). Expressões como "aprender sobre a natureza", "aprender sobre meio ambiente" são frequentes nessa visão, exemplificam bem essa corrente. Sob este viés, o objetivo da Educação Ambiental é reconstruir uma ligação entre os seres humanos e a natureza. 
No campo educacional, a abordagem naturalista se concretiza no cotidiano escolar na forma de atividades extraescolares, que visam sensibilizar sobre os problemas ambientais e a conservação/preservação da natureza, sem questionar e refletir sobre os aspectos socioeconômicos, políticos, éticos e culturais que envolvem o tema (RAMOS, 2006).

A corrente conservacionista/recursista agrupa expressões centradas na "conservação" de recursos naturais (SAUVĖ, 2005b). A ideia de que é necessário preservar os recursos naturais faz parte da educação familiar de muitas pessoas, é difundida pela mídia e implementada por ações escolares e comunitárias. São exemplos dessa corrente as concepções:

É um processo de conscientização sobre a preservação do meio ambiente e da vida nele, para a conservação dos recursos naturais (Prof.6).

A Educação Ambiental trata, [...] como podemos usar e conservar seus recursos, transformar e cuidar sem desrespeitar (Prof.3).

Estas concepções carregam uma certa preocupação com a forma como o planeta vem sendo administrado, demonstrando uma preocupação com a gestão ambiental. Para Philippi Junior e Pelicone (2014) esta visão conservacionista, com foco no manejo e preservação de recursos naturais, baseia-se nas ciências e na crença que a tecnologia solucionará os problemas gerados, sendo a causa destes, a falta de conhecimento e de comportamento adequado da população.

Outras correntes tradicionais que se destacaram nas concepções dos professores, foram a moral/ética, a humanista, a resolutiva e a sistêmica.

A corrente moral/ética é identificada em discursos que relacionam a formação de "valores" como um dos objetivos da Educação Ambiental, como podemos perceber em algumas concepções apresentadas:

[...]é a formação voltada para o desenvolvimento de valores e de uma consciência ecológica[...] (Prof.19).

É todo trabalho voltado a transmissão de valores éticos, [...] (Prof.16).

Para Sauvè (2005b), muitos educadores consideram que o alicerce da relação com o meio ambiente tem ordem ética e moral, devendo-se interferir de maneira a desenvolver valores ambientais. Segundo a autora, alguns educadores:

[...] convidam para a adoção de uma "moral" ambiental, prescrevendo um código de comportamentos socialmente desejáveis [...]; mas, mais fundamentalmente ainda, pode se 
tratar de desenvolver uma verdadeira "competência ética", e de construir seu próprio sistema de valores (SAUVÈ, 2005b, p.26)

Esta construção de valores, ético/morais, também pode ser percebida no discurso de Reigota (2008), no qual a Educação Ambiental é entendida como educação política, no sentido de preparar o ser humano ao exercício da cidadania, exigindo justiça social, ética nas relações sociais e com a natureza. $\mathrm{Na}$ concepção apresentada pelo Prof.12 identifica-se a corrente humanista.

Educação Ambiental são os processos pelos quais os sujeitos refletem e se reconstroem, socialmente e ambientalmente, a partir dos espaços que nos cercam, [...] (Prof.12).

Nesta corrente, Sauvè (2005b) destaca a dimensão humana do ambiente, construído no encontro da natureza com a cultura. Corresponde a um meio de vida, com dimensões históricas, culturais, políticas, econômicas, não podendo ser abordado sem se levar em conta sua significação e valor simbólico.

É um enfoque preferido, muitas vezes, pelos educadores que se interessam pela Educação Ambiental sob a ótica das ciências humanas. Ela exige mais rigor da observação, da análise e da síntese, mas também convoca para o sensorial, a sensibilidade afetiva, a criatividade (SAUVĖ, 2005b).

A corrente resolutiva, por sua vez, é centrada nos problemas do meio ambiente, na busca por informar ou levar as pessoas a se informar sobre problemáticas ambientais, assim como a desenvolver habilidades voltadas para resolvê-las (SAUVĖ, 2005). Esta encontra-se no discurso de alguns professores:

É a inserção de conteúdos e discussões [...], buscando soluções para a preservação da vida na terra (Prof.10).

[...], buscando a conservação dos recursos naturais, a resolução dos problemas que enfrentamos[...] (Prof.11)

A corrente Sistêmica, também identificada nas concepções, apoia-se nas contribuições da Ecologia e da Ciências Biológicas, cujos conceitos e princípios inspiraram o campo da ecologia humana. Seu enfoque leva ao conhecimento, a compreensão da realidade e da problemática ambiental, permite identificar diferentes elementos de um sistema ambiental e torna visível as relações entre esses, como as relações entre os elementos biofísicos e os elementos sociais de uma situação ambiental (SAUVÈ, 2005).

Identificou-se esta corrente nas concepções de alguns professores, como por exemplo: 
A Educação Ambiental trata de tudo relacionado com a natureza e o homem, e suas relações com os meios físicos e biológicos, identificando como podemos melhorá-lo [...] (Prof.3).

O ensino de conhecimentos e conteúdos voltados para o meio ambiente, que relaciona o dia-dia do ser humano, [...] e seu relacionamento com os elementos que os constituem (Prof.14).

Para Capra (2001) uma visão sistêmica permite ao ser humano visualizar e estabelecer relações de interdependência entre os elementos que envolvem o Planeta e atribuem sentidos para suas conexões, chamadas de "Teia da Vida", isto é, todo o elemento biótico ou abiótico, bem como os fenômenos naturais, que estão interligados e pertencentes à mesma e única teia.

Com relação as correntes mais recentes, foi possível identificar nas concepções apresentadas pelos professores as correntes da sustentabilidade, a da ecoeducação e a crítica.

A corrente denominada de ecoeducação está centrada na perspectiva da Educação Ambiental em aproveitar o ambiente para o desenvolvimento pessoal. Nesta, o meio ambiente é percebido como uma esfera de interação essencial para a ecoformação recebida sobre ambiente, pela interação com ele, ou para a sua transformação (SAUVĖ, 2005b). O meio ambiente é o agente transformador, que tem na Educação Ambiental sua ferramenta de transformação, como mostram os exemplos a seguir:

É uma prática voltada para a construção de valores, de
pertencimento e que sensibiliza o ser humano a partir do meio
ambiente, levando a compreensão da problemática ambiental
(Prof.8).
É a formação voltada para [...] uma consciência ecológica, de
pertencimento ao ambiente, [...] (Prof.19).

A corrente da ecoeducação está relacionada a ecopedagogia, uma pedagogia para a promoção da aprendizagem do sentido das coisas a partir da vida cotidiana, ou seja, toma-se consciência do meio ambiente, a partir de situações do nosso cotidiano. De acordo com Gadotti (2005, p. 20) "a formação está ligada ao espaço/tempo no qual se realizam concretamente as relações entre o ser humano e o meio ambiente".

As concepções relacionadas à corrente crítica apresentam visão emancipatória do homem e se propõe a analisar as dinâmicas sociais que se encontram na base das realidades e problemáticas ambientais e, a partir destas propor soluções para problemáticas ambientais (SAUVÈ, 2005). Se enquadram nessa corrente, concepções como: 
É um processo de conscientização sobre a preservação do meio ambiente e da vida nele, para a conservação dos recursos naturais [...] (Prof.6).

Educação Ambiental são os processos pelos quais os sujeitos refletem e se reconstroem[...] (Prof.12).

As respostas que apresentam o termo conscientizar, conscientização podem ser situadas na corrente de crítica social, uma vez que remetem a tomada de consciência, e esta, pressupõe uma crítica. Isso porque, a tomada de consciência é uma ação realizada pelo sujeito que foi interiorizada em forma de pensamento (SALADINI, 2008).

Identificou-se também a corrente da sustentabilidade, pautada no desenvolvimento sustentável. Trata-se de aprender a utilizar de forma racional os recursos disponíveis hoje para que haja suficientemente para todos e se possa assegurar as necessidades do amanhã.

Essa concepção foi identificada em expressões como "para a sustentação da vida do planeta", "sobrevivência e das futuras gerações", "pensando no nosso futuro e do planeta e busca um desenvolvimento que seja realmente sustentável" apresentadas por alguns professores.

A Educação Ambiental para a construção de sociedades sustentáveis faz parte de uma estratégia para transformar os modelos de produção de consumo da sociedade, em prol das gerações presentes e futuras.

Todas as correntes se mostram importantes no processo de educação, não havendo assim uma que seja ideal, mais adequada para ser adotada. Estas correntes podem coexistir, e, portanto, cabe ao professor identificar nelas, quais são seus objetivos como educador Ambiental, o que se pretende transmitir.

\section{Considerações Finais}

Frente ao objetivo do trabalho, que foi analisar as concepções de Meio Ambiente e Educação Ambiental dos professores e como estas são inseridas na prática pedagógica, constatou-se que as abordagens conceituais de Meio Ambiente e de Educação Ambiental estiveram representadas nas concepções naturalistas, recursistas e antropocêntricas, sendo abordadas em sala de aula através de metodologias convencionais, em que o aluno é sujeito passivo no processo de ensino-aprendizagem.

Constatou-se, ainda, algumas peculiaridades nas definições do termo "Meio Ambiente", estas às vezes confusas, que acabam levando às concepções de Educação Ambiental que apresentam apenas a preservação da natureza e seus recursos, como principal ponto de discussão, deixando à margem questões culturais, sociais, econômicas e políticas que estão intimamente ligadas a esta temática e a problemática ambiental. 
Tendo em vista que diferentes concepções de Meio Ambiente podem coexistir, deve-se compreender que estas influenciam os educadores na definição e práticas da Educação Ambiental, assim como, a concepção ambiental pode e deve interferir na forma como se concebe o Meio Ambiente e a Educação. Neste aspecto, os resultados revelaram que os professores não adotam uma única concepção de Educação Ambiental, mas sim inúmeras, que podem se complementar, e que tem relação direta com sua concepção de Meio Ambiente.

É necessário, portanto, que estes educadores tenham acesso a processos formativos no sentido de ampliar sua compreensão sobre os termos, conceitos e categorias. A relevância disto insere-se no entendimento de que as abordagens conceituais do meio ambiente e da Educação Ambiental devem estar associadas a uma visão contextualizada da realidade ambiental, com ênfase na incorporação de aspectos sócio-econômicos-culturais.

Nota: Esse artigo é parte integrante da dissertação de mestrado do autor intitulada Meio ambiente, desenvolvimento e o rural sustentável: concepções no Ensino Fundamental I. Aprovada no programa de Pós-Graduação em Desenvolvimento Rural Sustentável da Unioeste, Marechal Cândido Rondon, Paraná, Brasil.

\section{Agradecimentos}

À Universidade Estadual do Oeste do Paraná pela oferta do Programa de PósGraduação em Desenvolvimento Rural Sustentável e por tornar possível o grau de mestre do autor, e aos professores por participarem desta pesquisa.

\section{Referências}

BARDIN, L. Análise de conteúdo. 4. ed. Lisboa/Portugal: Edições70, 2010, 280 p.

BEZERRA, T. M. O.; FElICIANO, A. L. P.; ALVES, A. G. C. Percepção ambiental de alunos e professores do entorno da estação ecológica de Caetés - região metropolitana do Recife -PE. Revista Biotemas, Florianópolis, SC, v. 21, n.1, p. 147-160, 2008.

BRASIL. LEI 6.938/1981. Dispõe sobre a Política Nacional do Meio Ambiente, seus fins e mecanismos de formulação e aplicação e dá outras providências. Brasília, DF: Diário Oficial da União, 31 de agosto de 1981. Disponível em: http://www.planalto.gov.br/ccivil 03/LEIS/L6938.htm. Acesso em: 20 outubro 2019.

BRASIL. Lei no. 9795, de 27 de abril de 1999: dispõe sobre a Educação Ambiental, institui a Política Nacional de Educação Ambiental e dá outras providências. Brasília, DF: Diário Oficial da União, 28 abr. 1999. Disponível em: http://www.planalto.gov.br/ccivil 03/Leis/L9795.htm. Acesso em: 26 jun. 2013. 
CAPRA, F. A teia da vida: uma nova compreensão científica dos sistemas vivos. Tradução de Newton Roberval Eichemberg. 6. ed. São Paulo: Cultrix, 2001. $256 \mathrm{p}$.

CARNEIRO, S. M. M. Formação Inicial e Continuada de Educadores Ambientais. REMEA. v. especial, Rio Grande, RS, dezembro de 2008.

CARNIATTO, I. A Formação Inicial do Sujeito Professor: Investigação Narrativa em Ciências/Biologia. Coleção Thésis. Cascavel: Edunioeste, 2002. 158 p.

CARVALHO, I. C. de M. Educação Ambiental: a formação do sujeito ecológico. 6. ed. São Paulo: Cortez, 2012, 256 p.

DIAS, G. F. Educação Ambiental: princípios e práticas. 9. ed. São Paulo: Gaia, 2004. 551 p.

FERNANDES, E. C.; CUNHA, A. M. de O.; MARÇAL-JÚNIOR, O. Educação Ambiental e meio ambiente: Concepções de profissionais da educação. In: II Encontro Nacional de Pesquisadores em Educação Ambiental. 2002, São Carlos-SP. Anais[...]. Disponível em: http://www.abrapecnet.org.br/enpec/ivenpec/Arquivos/Painel/PNL123.pdf. Acesso em: 12 out. 2019.

GADOTTI, M. Pedagogia da Terra e Cultura de Sustentabilidade. Revista Lusófona de Educação. Campo Grande, Lisboa, Portugal, v. 6, n. 6, p 15-29, out. 2005.

GIANNUZZO, A. N. Los estudios sobre el ambiente y la ciência ambiental. Scientia e Studia, São Paulo, SP, v8, n.1, p. 129-156, 2010.

GIL, A. C. Como elaborar projetos de pesquisa. 4. ed. São Paulo: Atlas, 2002. $176 \mathrm{p}$.

GUIMARÃES, M. A formação de educadores ambientais. 3. ed. Campinas SP: Papirus, 2007. 174 p.

GUIMARÃES, M. Educação Ambiental Crítica. In: LAYRARGUES, P. P. (Org.). Identidades da Educação Ambiental brasileira. Ministério do Meio Ambiente. Diretoria de Educação Ambiental. Brasília: Ministério do Meio Ambiente, 2004, p.25-34. Disponível em: https://www.mma.gov.br/estruturas/educamb/ arquivos/livro ieab.pdf. Acesso em: 07 out 2019.

JACOBI, P. Meio ambiente urbano e sustentabilidade: alguns elementos para a reflexão. In: CAVALCANTI, C. (Org.). Meio ambiente, desenvolvimento sustentável e políticas públicas. São Paulo: Cortez, 1997. 436 p.

JACOBI, P. Educação Ambiental, Cidadania E Sustentabilidade. Cadernos de Pesquisa, São Paulo, SP, s/v., n. 118, p. 189-205, mar. 2003.

JACOBI, P. Educação Ambiental: o desafio da construção de um pensamento crítico, complexo e reflexivo. Educação e Pesquisa. São Paulo, SP, v. 31, n. 2, p. 233-250, 2005. 
LEFF, H. Saber Ambiental: sustentabilidade, racionalidade, complexidade, poder. 4. ed. Petrópolis, RJ: Vozes, 2014. 496p

OLIVEIRA, A. L.; OBARA, A. T.; RODRIGUES, M. A. Educação Ambiental: concepções e práticas de professores de ciências do ensino fundamental. Revista Electrónica de Enseñanza de las Ciências, Vigo, Espanha, v. 6, n. 3, p. 471-495, 2007.

PENTEADO, H. D. Meio ambiente e formação de professores, 5. ed. São Paulo: Cortez, 2003. 119 p. (Coleção Questões da Nossa Época, volume 38)

PHILIPPI JÚNIOR, A.; PELICIONI, M. C. F. Bases Políticas, Conceituais, Filosóficas e Ideológicas da Educação Ambiental. In: PHILIPPI JÚNIOR, A.; PELICIONI, M. C. F. (ed.) Educação Ambiental e sustentabilidade. 2. ed. revis. e ampli. Barueri, SP: Manole, p. 3-12. 2014.

RAMOS, E. C. A abordagem naturalista na Educação Ambiental. Uma análise dos projetos ambientais de educação em Curitiba. Tese (Doutorado em Ciências Humanas). Centro de Filosofia e Ciências Humanas. Universidade Federal de Santa Catarina, Florianópolis - SC, 2006. Disponível em: https://repositorio.ufsc.br/bitstream/handle/123456789/88656/227412.pdf?sequ ence=1\&isAllowed=y. Acesso em: 23 outubro 2019.

REIGOTA, M. O que é Educação Ambiental. 2. ed. Tatuapé, SP: Brasiliense, 2009. 63 p. (Coleção Primeiros Passos, volume 292)

REIGOTA, M. Meio ambiente e representação social. 7. ed. São Paulo, SP: Ed. Cortez, 2007. 87 p. (Questões da nossa época, volume 41)

REIGOTA, M. Cidadania e Educação Ambiental. Psicologia \& Sociedade. Sorocaba, SP, v. 20, n. especial, p. 61-69. 2008.

RICHARDSON, R. J. Pesquisa Social: métodos e técnicas. 3. ed. São Paulo: Atlas, 1999.

SALADINI, A. C. Da Ação à Reflexão: O Processo de Tomada de Consciência. Schème, Revista Eletrônica de Psicologia e Epistemologias Genéticas, Marília, SP, v. 1. n. 2, p. 31-54, jul./dez. 2008.

SAUVĖ, L. Educação Ambiental e desenvolvimento sustentável: uma análise complexa. Revista de Educação Pública, Mato Grosso v.6, n.10, p.72-103, 1997.

SAUVĖ, L. Educação Ambiental: possibilidades e limitações. Educação e Pesquisa, São Paulo. v. 31, n. 2, p. 317-322, maio/ago. 2005a.

SAUVÈ, L. Uma cartografia das correntes em Educação Ambiental. In: SATO, M.; CARVALHO, I. C. M. (Org.). Educação Ambiental: pesquisas e desafios. Porto Alegre, RS: Artmed, p. 17-46, 2005b. 
SAUVÈ, L.; ORELLANA, I.; QUALMAN, S. La educación ambiental: una relación constructiva entre la escuela y la comunidad. Guía de formación e intervención em educacion ambiental. EDAMAZ: Montreal, Canadá. 2000. 167 p.

SEGURA, D. S. B. Educação Ambiental na escola pública: da curiosidade ingênua à consciência crítica. São Paulo: Annablume/Fapesp, 2001. 214 p.

TAMAIO, I. O Professor na Construção do Conceito de Natureza: uma experiência de Educação Ambiental. São Paulo, SP: Annablumme/WWF, 2002. 158 p.

TOZONI-REIS, M. F. C. Temas ambientais como "temas geradores": contribuições para uma metodologia educativa ambiental crítica, transformadora e emancipatória. Educar, Curitiba, PR, n. 27, p. 93-110, jan./jun. 2006. Disponível em: http://www.scielo.br/pdf/er/n27/a07n27.pdf. Acesso em 12 fev. 2019. 